\title{
NADPH oxidase-dependent formation of reactive oxygen species contributes to angiotensin II-induced epithelial- mesenchymal transition in rat peritoneal mesothelial cells
}

\author{
JIE CHANG ${ }^{1}$, ZONGPEI JIANG ${ }^{1}$, HAIYAN ZHANG ${ }^{1}$, HENGMEI ZHU ${ }^{1}$, SHU-FENG ZHOU ${ }^{2}$ and XUEQING YU ${ }^{1}$ \\ ${ }^{1}$ Department of Nephrology, The First Affiliated Hospital, Sun Yat-sen University, \\ Guangzhou, P.R. China; ${ }^{2}$ School of Heath Sciences, RMIT University, Victoria, Australia
}

Received February 15, 2011; Accepted March 31, 2011

DOI: $10.3892 /$ ijmm.2011.683

\begin{abstract}
The objective of the present study was to investigate the role of NADPH oxidase-dependent formation of reactive oxygen species (ROS) in the angiotensin II (Ang II)-induced epithelial-mesenchymal transition (EMT) and in the accumulation of extracellular matrix (ECM) in rat peritoneal mesothelial cells (RPMCs). Primary cultured RPMCs were incubated with serum-free media for $24 \mathrm{~h}$ in order to arrest and synchronize cell growth. The cells were treated with Ang II $\left(10^{-7} \mathrm{M}\right)$ up to $48 \mathrm{~h}$. Cells were pretreated with an Ang II type I receptor antagonist (losartan, $10^{-5} \mathrm{M}$ ), or an inhibitor of NADPH, oxidase diphenyleneiodonium (DPI) $\left(10^{-5} \mathrm{M}\right)$, for $1 \mathrm{~h}$ before addition of Ang II. The dichlorofluorescein (DCF)sensitive cellular ROS were measured by fluorometric assay and confocal microscopy. RT-PCR was employed to detect the mRNA expression for the NADPH oxidase subunit p47phox, plasminogen activator inhibitor-1 (PAI-1), $\alpha$-smooth muscle actin ( $\alpha$-SMA) and E-cadherin. PAI-1, $\alpha$-SMA and p47phox protein expression were examined by Western blot analysis. Ang II significantly induced the production of intracellular ROS. DPI and losartan inhibited Ang II-induced ROS generation by $86.8 \%$ and $77.4 \%(\mathrm{p}<0.05)$, respectively. Ang II significantly stimulated NADPH oxidase subunit p47phox mRNA and protein expression in RPMCs. Both losartan and DPI inhibited Ang II-induced up-regulation of p47phox mRNA by $37.3 \%$ and $67.8 \%(\mathrm{p}<0.05)$, respectively. Ang II also stimulated $\alpha$-SMA mRNA and protein expression and down-regulated E-cadherin mRNA expression in RPMCs. This effect was suppressed by both losartan and DPI. Ang II significantly up-regulated PAI-1 mRNA and protein expression and these were significantly suppressed by both losartan and DPI. In conclusion, NADPH oxidase-dependent formation of
\end{abstract}

Correspondence to: Professor Zongpei Jiang, Department of Nephrology, The First Affiliated Hospital, Sun Yat-sen University, 58 Zhongshan Road II, Guangzhou 510080, P.R. China

E-mail: jx.home@medmail.com.cn

Key words: peritoneal mesothelial cells, reactive oxygen species, NADPH oxidase, angiotensin II
ROS mediates Ang II dependent EMT and accumulation of ECM in rat peritoneal mesothelial cells. NADPH oxidase may represent a potential therapeutic target in the management of peritoneal fibrosis.

\section{Introduction}

Peritoneal dialysis (PD) is regarded as an effective renal replacement therapy in end-stage renal disease (ESRD) patients. However, peritoneal fibrosis is one of the most important complications which eventually causes loss of ultrafiltration in peritoneal dialysis patients. The mechanism for peritoneal dialysis-related peritoneal fibrosis is unclear. Functional and structural alterations of the peritoneal mesothelial cells observed in patients are related to long-term continuous exposure of the monolayer to high concentration glucose, present in peritoneal dialysis solutions (1-3). Growing evidence demonstrates that the peritoneal mesothelial cells could undergo epithelial-mesenchymal transition (EMT) with resultant extracellular matrix (ECM) accumulation that can contribute to the development and progression of peritoneal fibrosis $(4,5)$. During EMT, mesothelial cells go through a transition from an epithelial to a mesenchymal phenotype, a transition also called transdifferentiation, when they are subjected to a variety of stimuli, such as glucose degradation products, advanced glycation end-products, transforming growth factors (TGFs), and angiotensin II (Ang II) (6-8).

The local renin-angiotensin system (RAS) has been implicated in the regulation of cellular activities in various tissues. Ang II, the main peptide of the RAS, has been recognized as a potent cytokine that regulates cell growth, inflammation, and fibrosis, contributing to the progression of renal disease (9). All components of the RAS can be found in the kidney, heart, and blood vessel wall (10). Noh et al (11) have demonstrated that human peritoneal mesothelial cells (HPMCs) constitutively express all components of the RAS. Exposure of mesothelial cells to high concentrations of glucose increases production of Ang II that, in turn mediates up-regulation of TGF- $\beta 1$ and fibronectin. Angiotensin converting enzyme inhibitors (ACEI) ameliorate peritoneal fibrosis in an encapsulating peritoneal sclerosis mouse model (12). Taken together, these observations support the notion 
that Ang II may play an important role in the development of peritoneal fibrosis in long-term PD patients. However, there is scant data regarding the effect of Ang II on EMT and ECM accumulation and the signal transduction pathways in HPMC remain unclear.

Oxidative stress has recently been suggested to be involved in cell growth, apoptosis, migration, and tissue fibrosis (13). Generation of reactive oxygen species (ROS) is regulated by cytokines and growth factors, such as Ang II, which increases $\mathrm{O}_{2}{ }^{-}$and $\mathrm{H}_{2} \mathrm{O}_{2}$ production in cardiac, vascular smooth muscle, endothelial and mesangial cells (14-18). Recent studies indicate that NADPH oxidase is a major source of ROS production in many non-phagocytic cells (14). Under physiological conditions, non-phagocytic NADPH oxidase has a very low-level constitutive activity. However, the enzymatic activity can be up-regulated both acutely and chronically in response to stimuli, such as Ang II. The NADPH oxidase-dependent formation of ROS can influence signaling molecules through alteration of the intracellular redox state and oxidative modification of proteins. In physiological conditions, these events play an important role in maintaining cellular function and integrity. In contrast, ROS contribute to cell dysfunction and remodeling through oxidative damage under pathological conditions (15).

It has been demonstrated that Ang II up-regulates NADPH oxidase, accompanied by increased formation of ROS in cardiocytes $(15,16)$, endothelial cells $(17)$, vascular smooth muscle cells (18), and hepatic stellate cells (19). However, it is unclear whether Ang II-induced peritoneal fibrosis is associated with the formation of NADPH oxidase-dependent ROS. Therefore, this study was performed to examine whether NADPH oxidase could mediate the Ang II-induced EMT and the accumulation of ECM in rat peritoneal mesothelial cells (RPMCs).

\section{Materials and methods}

Chemicals and reagents. Ang II was purchased from SigmaAldrich (St. Louis, MO). Trypsin, ethylenediamine tetraacetic acid (EDTA), Dulbecco's modified Eagle's medium (DMEM)F12 medium were all from Invitrogen (Carlsbad, CA). Merck, Sharp \& Dohme Pty, Ltd. (Whitehouse Station, NJ) kindly provided losartan.

Cell culture. Rat primary peritoneal mesothelial cells were isolated as previously described (20). In brief, healthy male Sprague-Dawley rats weighing $\sim 150 \mathrm{~g}$ were anesthetized. Approximately 20-30 ml of phosphate-buffered saline (PBS) containing $0.25 \%$ trypsin and $0.02 \%$ EDTA was infused into the peritoneal cavity and rinsed for $90 \mathrm{~min}$. Sediments from the recovered fluids were cultured in DMEM-F12 medium supplemented with $10 \%$ fetal bovine serum (FBS). The cultures were passaged 2-3 times before experiments. The isolated cells were examined by phase contrast microscope, electron microscope and immunohistochemical analysis to confirm the cell phenotypes. The research was conducted in accordance with the Guide for Care and Use of Laboratory Animals as adopted and promulgated by the United States National Institutes of Health. All experimental protocols were approved by the Review Committee for the Use of Human or Animal Subjects of the Sun Yat-sen University.
Experimental conditions. Primary RPMCs were cultured in DMEM-F12 containing 10\% FBS. Subconfluent mesothelial cells were incubated with serum-free media for $24 \mathrm{~h}$ to arrest and synchronize the cell growth. The cells were treated with fresh serum-free DMEM/F12 containing Ang II $\left(10^{-7} \mathrm{M}\right)$. Some groups of cells were pretreated with the Ang II type I receptor antagonist losartan $\left(10^{-5} \mathrm{M}\right)$ or the NADPH oxidase inhibitor diphenyleneiodonium (DPI) $\left(10^{-5} \mathrm{M}\right)$ for $1 \mathrm{~h}$ before Ang II addition. The cells were harvested at 8 or $24 \mathrm{~h}$ for analysis. The control group was cultured under non-stimulating conditions.

Assay of ROS. Intracellular ROS production was measured as described by Ha et al (21). 2',7'-Dichlorodihydro-fluorescein diacetate $\left(\mathrm{H}_{2} \mathrm{DCFH}-\mathrm{DA}\right)$ (Molecular Probes Inc., Eugene, OR, USA) is a nonpolar compound that is converted into a non-fluorescent polar derivative $\left(\mathrm{H}_{2} \mathrm{DCFH}\right)$ by a cellular esterase after incorporation into cells. $\mathrm{H}_{2} \mathrm{DCFH}$ is rapidly oxidized to the highly fluorescent DCF in the presence of intracellular hydrogen peroxide and peroxidases. Serum-starved cells on round coverslips were incubated with $\mathrm{H}_{2}$ DCFH-DA for $15 \mathrm{~min}$ at $37^{\circ} \mathrm{C}$. The cells were stimulated with Ang II and then immediately observed by a laser scanning confocal microscope. The samples were excited by a 488-nm Argon laser and images were filtered by a longpass 505-nm filter. Cells were randomly assigned to separate experiments and DCF fluorescence intensities of treated cells were compared with those of untreated control cells.

Reverse transcription-polymerase chain reaction (RT-PCR). The mRNA levels of the NADPH oxidase subunits, p47phox, p67phox, p22phox, gp91phox and PAI-1, E-cadherin, $\alpha$-SMA were assessed by RT-PCR. Total RNA from RPMCs was extracted using the TRIzol reagent (Invitrogen), and converted into cDNA with the MBI RevertAid ${ }^{\mathrm{TM}}$ First Strand cDNA synthesis system (Invitrogen) according to the manufacturer's manual. Subsequently, the PCR was performed using the MBI system (Invitrogen). The forward and reverse primers used in this study are shown in Table I. The amplification was performed with the following cycle: $94^{\circ} \mathrm{C}$ for $5 \mathrm{~min}, 94^{\circ} \mathrm{C}$ for $30 \mathrm{sec}, 53^{\circ} \mathrm{C}$ for $30 \mathrm{sec}, 72^{\circ} \mathrm{C}$ for $45 \mathrm{sec}$, and $72^{\circ} \mathrm{C}$ for $10 \mathrm{~min}$ (the annealing temperature varied among the different primers). Each sample was tested in triplicate. To confirm the amplification specification, the PCR products were subjected to a melting curve analysis and subsequent agarose gel electrophoresis. The results were normalized to GAPDH and expressed as the relative changes compared to the control.

Western blot analysis. The protein levels of $\alpha$-SMA, PAI-1 and $\mathrm{p} 47$ phox were examined by Western blotting as described by Rhyu et al (22). At the end of the incubation, cells were washed with PBS and lysed in $150 \mu$ l of lysis buffer containing protease inhibitors for $5 \mathrm{~min}$ on ice. Conditioned media and cell lysates were centrifuged at $5,000 \mathrm{x} \mathrm{g}$ at $4^{\circ} \mathrm{C}$ for $15 \mathrm{~min}$, and the concentration of the cellular proteins was determined using the Bio-Rad assay (Bio-Rad Laboratories, Hercules, CA). Samples with equal concentrations of cellular protein $(30 \mu \mathrm{g})$ were mixed with a $5 \mathrm{X}$ sample buffer, heated at $95^{\circ} \mathrm{C}$ for $10 \mathrm{~min}$ and separated on $10 \%$ SDS-polyacrylamide gels. After electrophoresis for $90 \mathrm{~min}$, the proteins were transferred 
Table I. Primer sequences for RT-PCR.

\begin{tabular}{|c|c|c|}
\hline Primer & Sequence & Size (bp) \\
\hline GAPDH & $\begin{array}{l}\text { Sense 5'-ATG GTC TAC ATG TTC CAG TA-3' } \\
\text { Antisense 5'-TCA GAT CCA CAA CGG ATA CA-3' }\end{array}$ & 590 \\
\hline p47phox & $\begin{array}{l}\text { Sense 5'-CTG TCT GAG GGT GAA GCC ATC-3' } \\
\text { Antisense 5'-GGA ATC GGA CGC TGT TGC G-3' }\end{array}$ & 259 \\
\hline p67phox & $\begin{array}{l}\text { Sense 5'-CGA GGG AAC CAG CTG ATA GA-3' } \\
\text { Antisense 5'-CAT AGG CAC GCT GAG CTT CA-3' }\end{array}$ & 740 \\
\hline p22phox & $\begin{array}{l}\text { Sense 5'-GAC GCT TCA CGC AGT GGT ACT-3' } \\
\text { Antisense 5'-CAC GAC CTC ATC TGT CAC TGG-3' }\end{array}$ & 485 \\
\hline gp91phox & $\begin{array}{l}\text { Sense 5'-ATT CAA GAT GGA GGT GGG ACA-3' } \\
\text { Antisense 5'-AAT GGA GGC AAA GGG CGT-3' }\end{array}$ & 310 \\
\hline$\alpha$-SMA & $\begin{array}{l}\text { Sense 5'-GCT CTG TAA GGC GGG CTT TG-3' } \\
\text { Antisense 5'-ACG AAG GAA TAG CCA CGC TCA-3' }\end{array}$ & 558 \\
\hline E-cadherin & $\begin{array}{l}\text { Sense 5'-CAG GAT TAC AAG TTC CCG CCA-3' } \\
\text { Antisense 5'-CAC TGT CCG CTG CCT TCA G-3' }\end{array}$ & 354 \\
\hline PAI-1 & $\begin{array}{l}\text { Sense 5'-ATG GAA CAA GAA TGA GAT CA-3' } \\
\text { Antisense 5'-TCA AAG GGT GCT GCA ATG AAC-3' }\end{array}$ & 471 \\
\hline
\end{tabular}

onto a nitrocellulose membrane using a transblot chamber with Tris buffer (0.025 M Tris-HCl, $0.192 \mathrm{M}$ glycine, and 20\% $\mathrm{MeOH})$. The membrane was blocked for $1 \mathrm{~h}$ at room temperature with $5 \%$ nonfat milk in TBS-Tween-20. Membranes were incubated at $4^{\circ} \mathrm{C}$ overnight with antibodies against $\alpha$-SMA (Dako, Denmark), PAI-1 (Santa Cruz Biotechnology, Santa Cruz, CA, USA) or p47phox (Upstate USA Inc., Charlottesville, VA), respectively. After extensive washing in TBS-Tween-20, the membranes were incubated with peroxidase-conjugated secondary anti-mouse IgG or anti-rabbit IgG (Cell Signaling Technology Inc., Danvers, MA, USA) for $1 \mathrm{~h}$ at room temperature. After washing, the membranes were incubated with the enhanced chemiluminescence system (ECL) detection kit. Positive immunoreactive bands were quantified densitometrically, normalized to GAPDH and compared with controls.

Statistical analysis. All results are expressed as the mean $\pm \mathrm{SEM}$ of $n$ experiments. Analysis of variance (ANOVA) was used to assess the differences between multiple groups using SPSS11.0 software (SPSS Inc., Chicago, IL). A value of $\mathrm{p}<0.05$ was used as the criterion for a statistically significant difference.

\section{Results}

Characterization of cultured RPMCs. The confluent RPMCs showed a uniform cobblestone-like appearance under the phase contrast microscope. Immunohistochemical studies revealed a positive staining for cytokeratin and vimentin, but a negative staining for Factor VIII associated antigen and CD45 (data not shown).

Effect of DPI and losartan on Ang II -induced ROS generation in RPMCs. Treatment with Ang II $\left(10^{-7} \mathrm{M}\right)$ for 15 min induced the production of DCF-sensitive cellular ROS by $3.64 \pm 0.53$ fold compared with the control $(\mathrm{p}<0.05)$. Both losartan $(10 \mu \mathrm{M})$ and DPI $(10 \mu \mathrm{M})$ effectively inhibited Ang II-induced
A

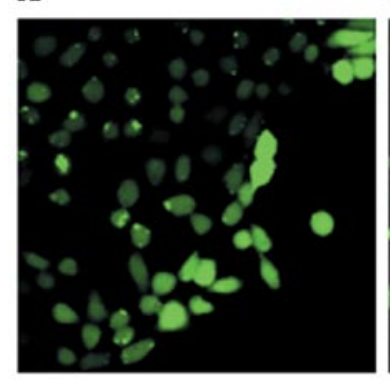

B

C

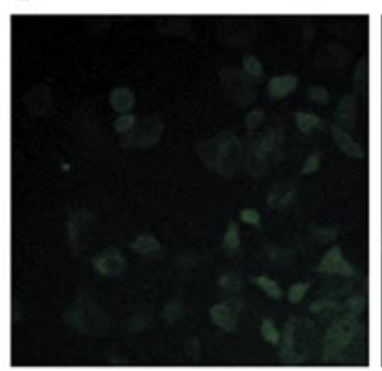

D

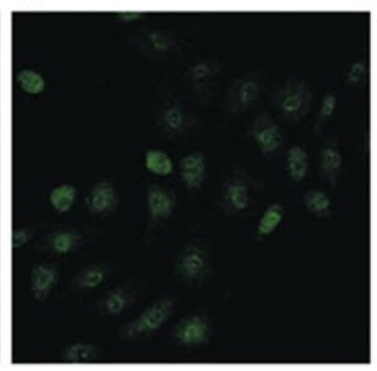

Figure 1. Effect of losartan and DPI on Ang II-induced cellular reactive oxygen species (ROS) formation in rat peritoneal mesothelial cells. After incubation of quiescent cells, DCF-sensitive cellular ROS generation was measured as described in Materials and methods. Losartan and DPI were administrated $1 \mathrm{~h}$ before addition of Ang II, and cellular ROS levels were measured at $15 \mathrm{~min}$ after the addition of Ang II. Each group of the ROS levels were described by fold-changes relative to the control group. (A) control group; (B) Ang II $\left(10^{-7} \mathrm{M}\right)$; (C) DPI $(10 \mu \mathrm{M})+$ Ang II $\left(10^{-7} \mathrm{M}\right)$; (D) losartan $(10 \mu \mathrm{M})+$ Ang II $\left(10^{-7} \mathrm{M}\right)$.

ROS generation by $77.4 \%(\mathrm{p}<0.05)$ and $86.8 \%(\mathrm{p}<0.05)$, respectively, compared with the cells treated with Ang II alone (Fig. 1).

Effect of losartan and DPI on the Ang II-induced p47phox overexpression in RPMCs. Ang II stimulated the mRNA 
A

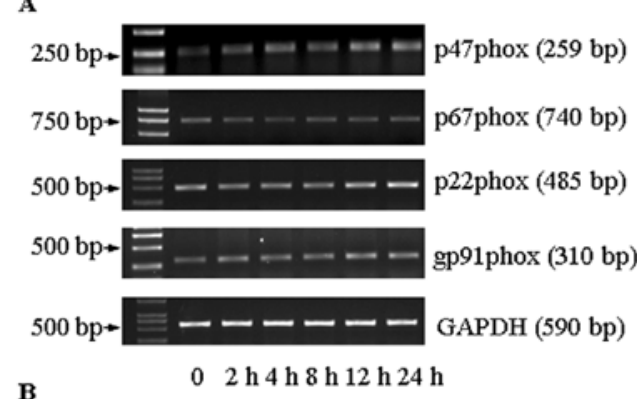

B

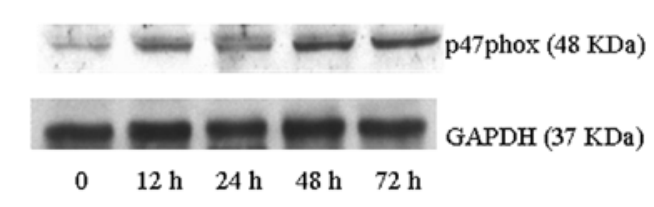

C

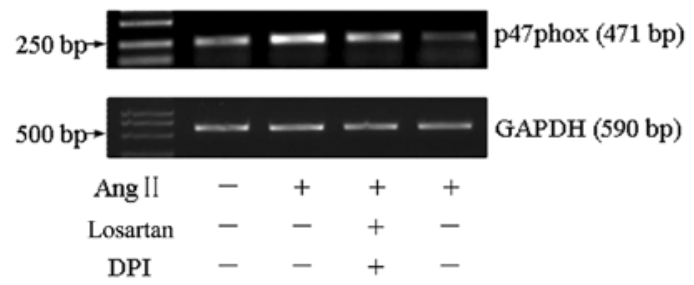

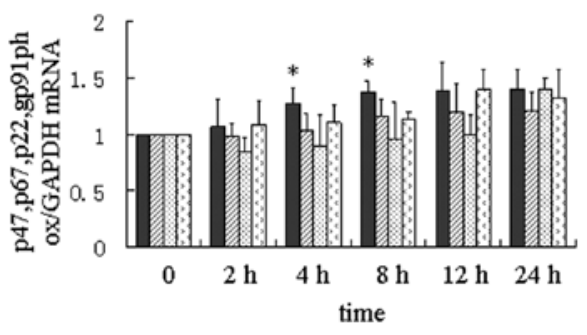

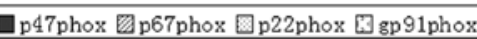
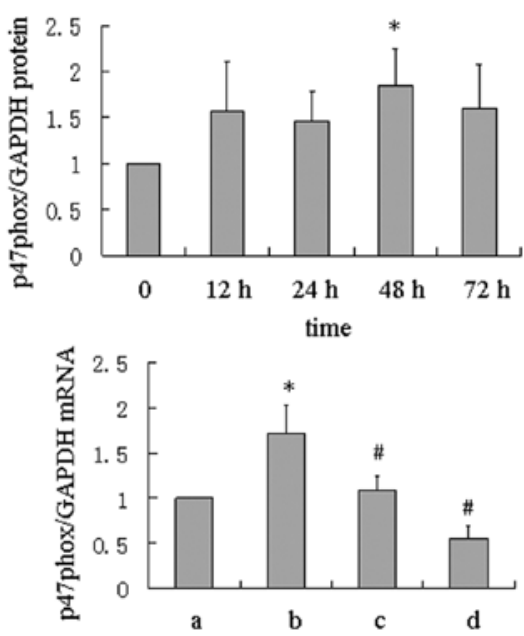

Figure 2. Ang II induced the mRNA expression of NADPH oxidase subunits and the effect of losartan and DPI on the NADPH oxidase p47phox subunit expression in RPMCs. (A) The Ang II-induced mRNA expression of the NADPH oxidase subunits in RPMCs was measured by RT-PCR. (B) p47phox protein synthesis was examined by Western blot analysis. (C) The effect of losartan and DPI on the mRNA expression of the NADPH oxidase, p47phox subunit, were assessed by RT-PCR. RT-PCR for p47phox and other subunits was performed at $8 \mathrm{~h}$ after Ang II treatment. a, control group; b, Ang II (10 ${ }^{-7} \mathrm{M}$ ); $\mathrm{c}$, losartan $(10 \mu \mathrm{M})+$ Ang II $\left(10^{-7} \mathrm{M}\right) ; \mathrm{d}$, DPI $(10 \mu \mathrm{M})+$ Ang II $\left(10^{-7} \mathrm{M}\right)$. The results were measured by the fold-changes in the ratio of p47phox and other subunits/ GAPDH relative to the control group. Values are expressed as the mean \pm SEM of three experiments. ${ }^{*} \mathrm{p}<0.05$ vs. the $0 \mathrm{~h}$ or control group; ${ }^{\sharp} \mathrm{p}<0.05 \mathrm{vs}$. the Ang II group.

expression of the NADPH oxidase subunit, p47phox (Fig. 2A) between 4-8 h compared to control cells, but had no significant effect on the expression of the p67phox, p22phox and gp91phox subunits of NADPH oxidase. Accordingly, the p47phox protein expression was also up-regulated by Ang II, reaching a maximum effect at $48 \mathrm{~h}(\mathrm{p}<0.05)$ (Fig. 2B). Losartan $(10 \mu \mathrm{M})$ and DPI $(10 \mu \mathrm{M})$ effectively inhibited the up-regulation of p47phox mRNA expression by $37.3 \%(\mathrm{p}<0.05)$ and $67.8 \%$ $(\mathrm{p}<0.05)$, respectively, compared with the cells treated with Ang II alone (Fig. 2C).

Effect of losartan and DPI on AngII-induced $\alpha$-SMA expression in RPMCs. As shown in Fig. 3, Ang II led to $\alpha-S M A$ mRNA overexpression (Fig. 3A) from 2-12 h compared with control cells, while the $\alpha$-SMA protein expression (Fig. 3B) was also up-regulated by Ang II over $72 \mathrm{~h}(\mathrm{p}<0.05)$.

Treatment with losartan $(10 \mu \mathrm{M})$ or DPI $(10 \mu \mathrm{M})$ effectively down-regulated Ang II-induced $\alpha$-SMA mRNA overexpression in RPMCs by $25.4 \%(\mathrm{p}<0.05)$ and $45.4 \%(\mathrm{p}<0.05)$, respectively (Fig. 3C), whereas $\alpha$-SMA protein expression (Fig. 3D) was inhibited by $50.3 \%(\mathrm{p}<0.05)$ and $56.1 \%(\mathrm{p}<0.05)$, respectively. Neither losartan nor DPI affected the basal $\alpha$-SMA mRNA and protein expression in RPMCs (data not shown).

Effect of losartan and DPI on AngII-induced E-cadherin expression in RPMCs. Ang II significantly decreased E-cadherin
mRNA expression (Fig. 4A) at 12 and $24 \mathrm{~h}(\mathrm{p}<0.05)$ in RPMCs. The Ang II-induced down-regulation of E-cadherin mRNA was effectively attenuated by pretreatment with losartan or DPI by $63.8 \%(\mathrm{p}<0.05)$ and $49.1 \%(\mathrm{p}<0.05)$, respectively (Fig. 4B). Neither losartan nor DPI affected basal E-cadherin mRNA expression in RPMCs (data not shown). The data of the E-cadherin protein expression could not be obtained due to technical difficulties with the E-cadherin antibody.

Effect of losartan and DPI on Ang II-induced PAI-I expression in RPMCs. As shown in Fig. 5, Ang II significantly up-regulated PAI-1 mRNA expression (Fig. 5A) in a timedependent manner from 2-12 h $(\mathrm{p}<0.05)$. The Ang II-induced PAI-1 mRNA overexpression was significantly suppressed by $62.1 \%$ with losartan, and by $52.3 \%$ with DPI ( $<<0.05)$ (Fig 5B). Meanwhile, its protein overexpression was also attenuated by 46.6 and $46.8 \%$ with losartan and DPI, respectively $(\mathrm{p}<0.05)$ (Fig. 5C). However, losartan and DPI did not affect the basal PAI-1 expression in RPMCs (data not shown).

\section{Discussion}

Our data demonstrate that upon exposure to Ang II, RPMCs undergo a transition from an epithelial to a mesenchymal phenotype, as reflected by the up-regulation of $\alpha$-SMA and the down-regulation of E-cadherin expression. Noh et al (11) 

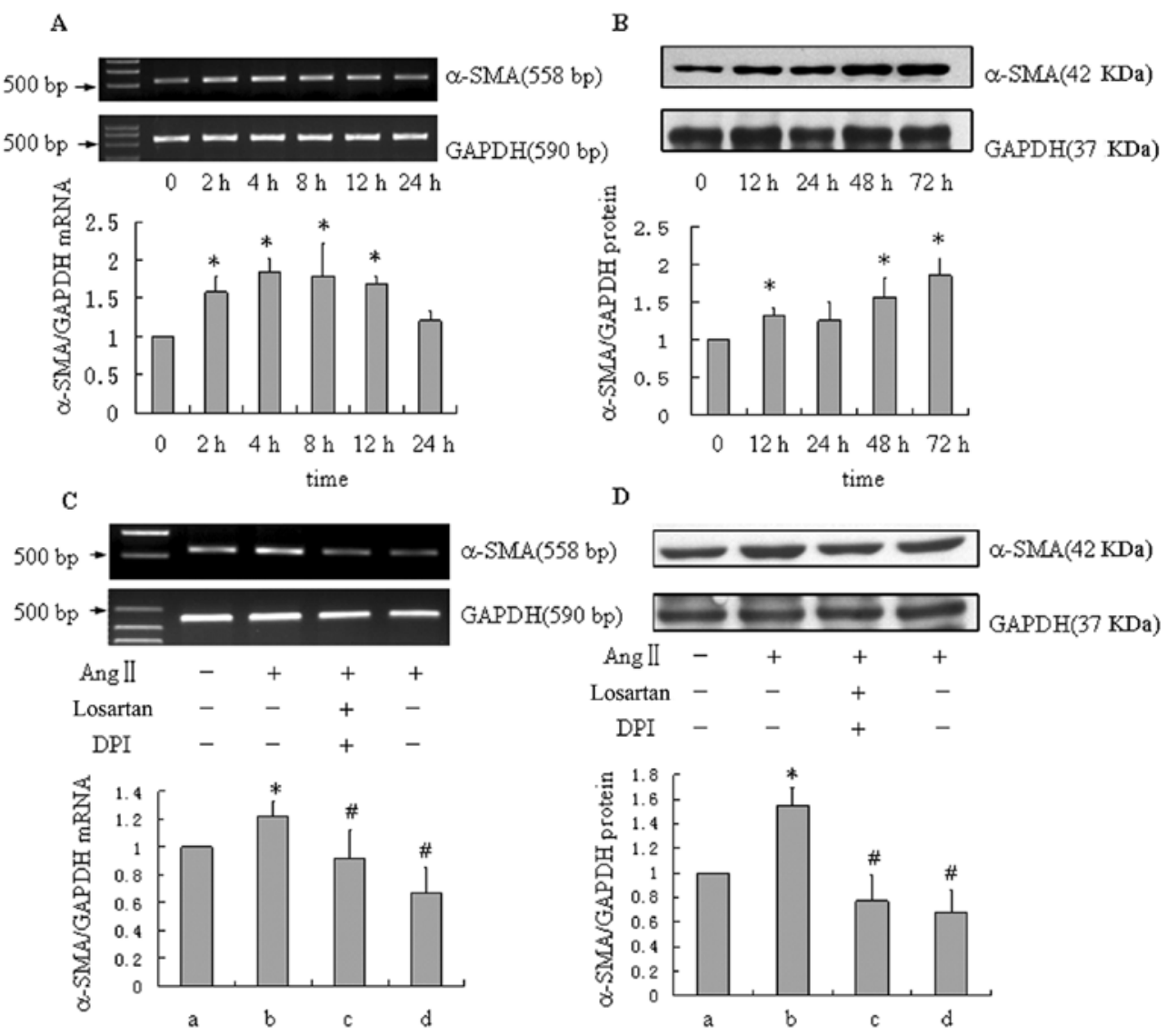

Figure 3. Effect of losartan and DPI on the Ang II-induced $\alpha$-SMA expression in RPMCs. After incubation of RPMCs, $\alpha$-SMA mRNA expression (A) was evaluated by RT-PCR. (B) Aliquots of the cell lysate were subjected to Western blot analysis to assess $\alpha$-SMA protein synthesis. (C) $\alpha$-SMA mRNA expression was evaluated with $10^{-7} \mathrm{M}$ AngII at $8 \mathrm{~h}$ while (D) the $\alpha$-SMA protein expression was assessed at $24 \mathrm{~h}$ after Ang II treatment. a, control group; b, Ang II $\left(10^{-7} \mathrm{M}\right) ; \mathrm{c}$, losartan $(10 \mu \mathrm{M})+$ Ang II $\left(10^{-7} \mathrm{M}\right)$; d, DPI $(10 \mu \mathrm{M})+$ Ang II $\left(10^{-7} \mathrm{M}\right)$. The results were measured by the fold-changes in the $\alpha$-SMA/GAPDH ratio relative to the control group. Values are expressed as the mean \pm SEM of three experiments. " $\mathrm{p}<0.05$ vs. the control or $0 \mathrm{~h}$ group; ${ }^{*} \mathrm{p}<0.05 \mathrm{vs}$. the Ang II group.

A
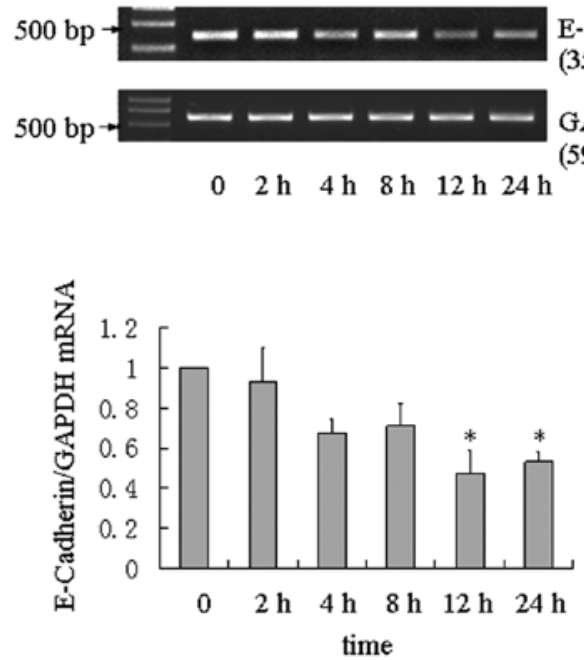

B
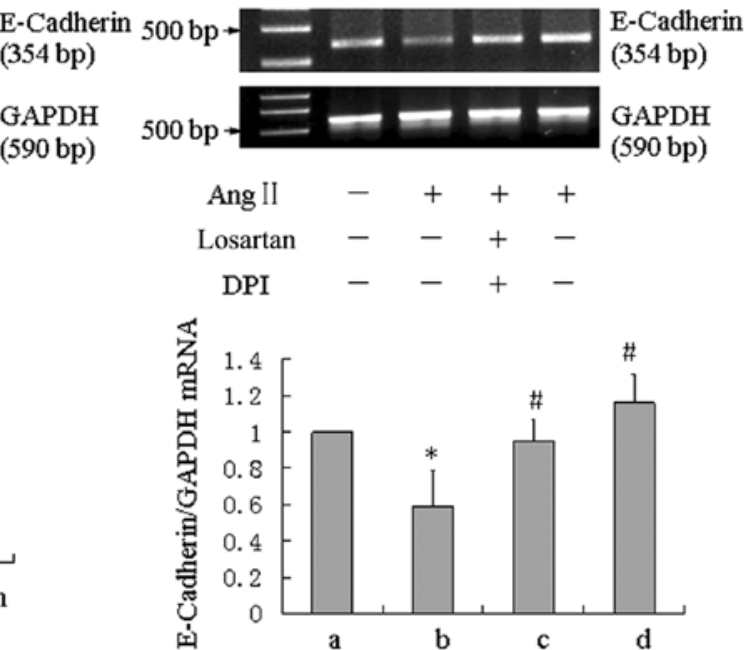

Figure 4. Effect of losartan and DPI on Ang II-induced E-cadherin expression in RPMCs. (A) After incubation of RPMCs, E-cadherin mRNA expression was measured by RT-PCR. (B) E-cadherin mRNA expression was evaluated with $10^{-7} \mathrm{M}$ Ang II at $8 \mathrm{~h}$ after Ang II treatment. a, control group; b, Ang II (10 $0^{-7} \mathrm{M}$ ); c, losartan $(10 \mu \mathrm{M})+$ Ang II $\left(10^{-7} \mathrm{M}\right)$; d, DPI $(10 \mu \mathrm{M})+$ Ang II $\left(10^{-7} \mathrm{M}\right)$. The results were measured by the fold-changes in the E-cadherin/GAPDH ratio relative to the control group. Values are expressed as the mean \pm SEM of three experiments. ${ }^{*} \mathrm{p}<0.05$ vs. the control or $0 \mathrm{~h}$ group; ${ }^{\#} \mathrm{p}<0.05$ vs. the Ang II group.

have reported that local RAS is physiologically active in peritoneal mesothelial cells and high glucose increases the expression of angiotensinogen, ACE, AT1 and AT2 receptors in RPMCs. The generation and secretion of Ang II induced by hyperglycemia plays a particularly important role in the development of peritoneal fibrosis. Blocking the effects of 
A
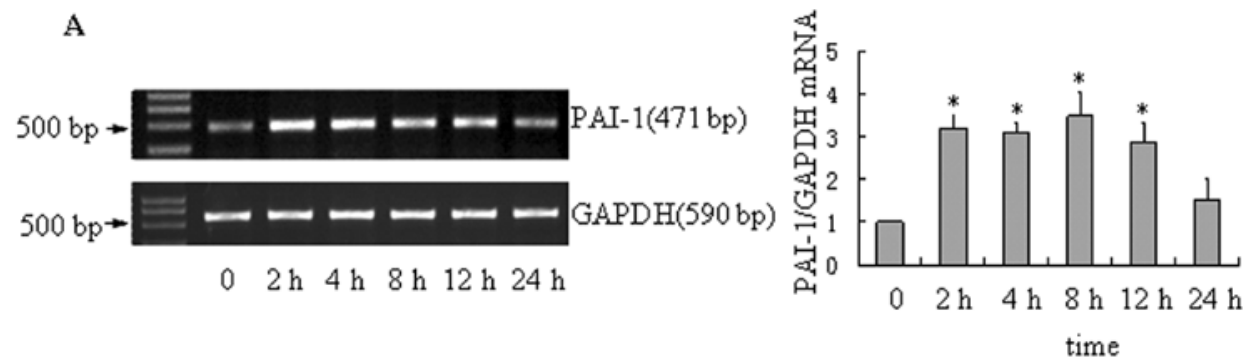

B
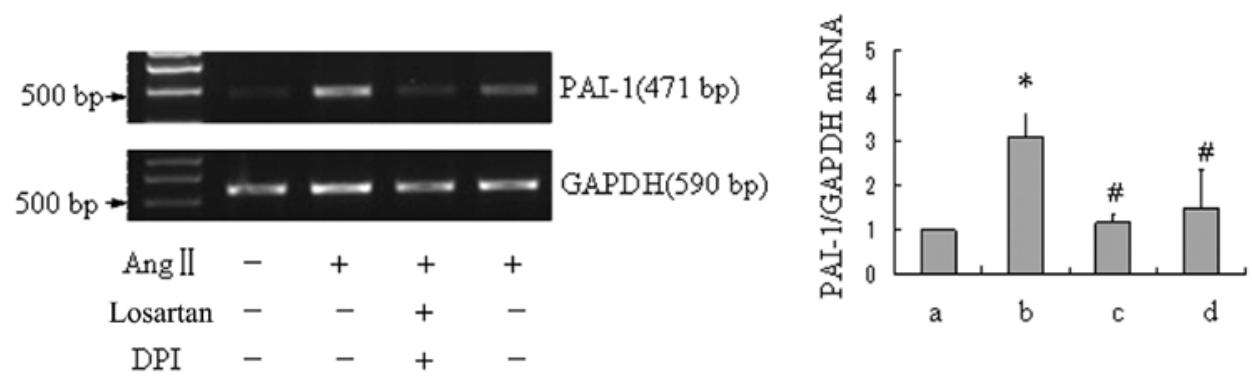

C
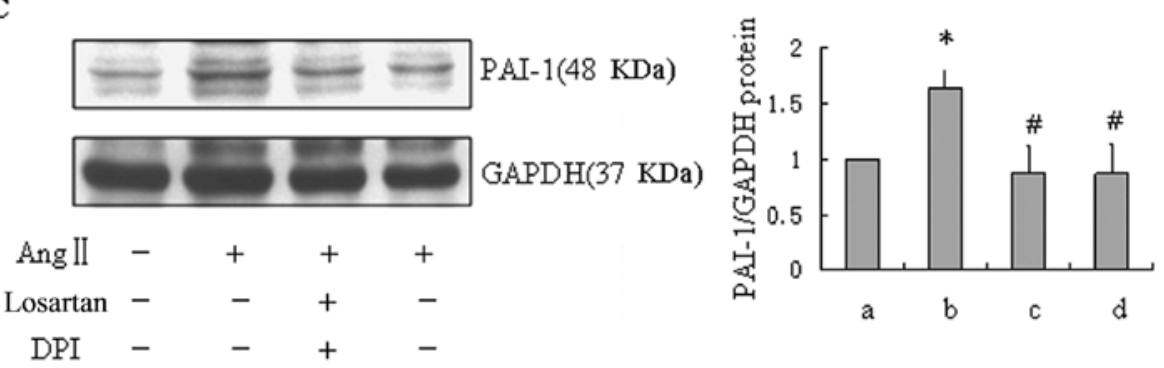

Figure 5. Effect of losartan and DPI on Ang II-induced PAI-1 expression in RPMCs. (A) After incubation of RPMCs, PAI-1 mRNA expression was assessed by RT-PCR. PAI-1 mRNA (B) and protein expression (C) after Ang II treatment were evaluated by RT-PCR and Western blot analysis, respectively. a, control group; b, Ang II $\left(10^{-7} \mathrm{M}\right)$; c, losartan $(10 \mu \mathrm{M})+\operatorname{Ang} \mathrm{II}\left(10^{-7} \mathrm{M}\right)$; d, DPI $(10 \mu \mathrm{M})+$ Ang II $\left(10^{-7} \mathrm{M}\right)$. The results were measured by the fold-changes in the PAII- $1 /$ GAPDH ratio relative to the control group. Values are expressed as the mean \pm SEM of three experiments. ${ }^{*} \mathrm{p}<0.05$ vs. the control or $0 \mathrm{~h}$ group; ${ }^{*} \mathrm{p}<0.05 \mathrm{vs}$. the Ang II group.

Ang II either by ACEI or Ang II receptor blockers (ARB) has been demonstrated to successfully prevent EMT and fibrogenesis by blocking its hemodynamic and non-hemodynamic actions in human proximal tubular cells (23), and mesangial cells $(24,25)$. This is the first study to demonstrate that the Ang II-induced EMT is effectively prevented by losartan in RPMCs.

For many years, EMT has been thought to be an important source of myofibroblasts, which are regarded as the major contributor of EMC overproduction (26). In addition, PAI-1 plays an important role in remodeling of the ECM (27). PAI-1 is overexpressed in pathological conditions associated with renal fibrosis, including diabetic nephropathy. However, the role of PAI-1 and its signaling pathways in peritoneal fibrosis are unknown. We found that Ang II increased both PAI-1 mRNA and protein expression and losartan effectively inhibited the process of EMT in RPMCs, suggesting that PAI-1 probably acts through the AT1 receptor. Our results imply that in addition to having antihypertensive and renal-protective effects, combination therapy with an Ang II receptor blocker may also be effective in preventing loss of peritoneal function and slowing down peritoneal fibrosis. Taken together, our observations demonstrate that Ang II could induce EMT and the accumulation of ECM in RPMCs.
Although a number of recent studies have demonstrated that Ang II may be a major contributor in regulating peritoneal mesothelial cell transdifferentiation and the accumulation of ECM, the mechanism of Ang II action is not fully understood. Its signaling pathways have received much attention in recent years, and ROS have been shown to mediate Ang II-induced cellular responses in various types of cells. As intracellular messengers and signaling molecules, ROS activate signal transduction cascades and transcription factors and up-regulate TGF- $\beta 1$ and ECM genes and proteins (28). As previously reported in vascular smooth muscle (18) and endothelial cells (16), we observed that exogenous Ang II induced the increase of ROS production in rat peritoneal mesothelial cells and losartan could inhibit the up-regulation of ROS.

NADPH oxidase is an important enzyme source of intracellular ROS formation. The NADPH oxidase consists of four components that are essential for its activity: the membraneassociated cytochrome, b558, composed of one p22phox and one gp91phox subunit; the cytosolic components, p47phox and p67phox; and the small GTPases, Rac1 or Rac2. Under stimulation, in resting phagocytes, the unassembled and inactive oxidase becomes active after translocation of cytosolic components to the membrane $(14,29,30)$. Activation of NADPH oxidase requires the translocation of the cytosolic factors, 
p47phox and p67phox, to the membrane subunits, including p22phox and gp91phox (31).

To date, the exact function and regulation of every subunit in the activation of NADPH oxidase is not very clear. Evidence that $\mathrm{p} 47$ phox plays a key role in NADPH oxidase activation comes in part from $\mathrm{p} 47$ phox(-/-) knock-out mice, which exhibit significantly lower Ang II-induced superoxide production in endothelial cells (32) . It appears that p47phox is required for the assembly of a stable complex of cytosolic subunits with membrane-bound cytochrome b558 and the recruitment of p67phox. The deletion or substitution of residues in the SH3 domains of p47phox disrupts the p47phox interaction with p67phox and leads to the defective activation of the enzyme both in vivo and in vitro (33). However, in contrast with the well-recognized role of NADPH oxidase in the cardiovascular system, very limited information is available regarding the role of NADPH oxidase in Ang II-induced peritoneal fibrosis. Our data demonstrate that Ang II may induce the up-regulation of both NADPH oxidase p47phox mRNA expression and protein synthesis as well as ROS generation, but has no significant effect on the expression of other subunits of the NADPH oxidase, such as p67phox, p22phox and gp91phox. These observations imply that $\mathrm{p} 47 \mathrm{phox}$ may be a critical component and may play an important role in NADPH oxidase activation and catalysis in the formation of ROS.

We found that Ang II induced $\mathrm{O}_{2}^{-}$overproduction in RPMCs, most likely via the NADPH oxidase-dependent mechanism. This excess $\mathrm{O}_{2}^{-}$generation was blocked by DPI, the inhibitor of NADPH oxidase, suggesting that the effect of Ang II on $\mathrm{O}_{2}^{-}$production is mediated by the activition of NADPH oxidase system. Moreover, we found that DPI prevented Ang II-induced p47phox mRNA up-regulation in cultured RPMCs. Taken together, DPI not only prevents the activity of this enzyme which contributes to the production of ROS, but also affects the transcription and translation of the p47phox subunit.

In the present study, we also found that the transdifferential responses induced by Ang II, including the overexpression of $\alpha$-SMA and PAI-1 and the down-regulation of E-cadherin in RPMCs could be significantly reversed by pre-treatment with DPI. It is strongly suggested that the NADPH oxidase may be an important mediator of the development of the EMT and the accumulation of ECM induced by Ang II. We can imply that the NADPH oxidase-produced ROS, function as important intracellular second messengers to modulate many downstream signaling cascades, leading to the expression of growth factors, such as TGF- $\beta 1$, pro-inflammatory mediators, and modification of the ECM (28). All these events contribute to fibrosis. Other studies have reported that Ang II induces fibronectin expression via ERK1/2 and p38 MAPK in human peritoneal mesothelial cells (34); high glucose up-regulates TGF- $\beta 1$ and fibronectin expression through activation of protein kinase $\mathrm{C}$ and that ROS amplifies protein kinase $\mathrm{C}$ signaling in HPMCs (5). Altogether, these data imply that NADPH oxidase-dependent ROS formation is a common mechanism involved in Ang II-induced EMT and accumulation of ECM. Furthermore, in vivo studies are required to confirm whether these effects of losartan or DPI which were observed in an in vitro system on cultured RPMC, can also be translated in vivo.
Based on our findings, we can speculate that NADPH oxidase is involved in the EMT process and contributes to the Ang II-induced ECM accumulation. The changes of p47phox, $\alpha$-SMA and PAI in RPMCs treated with Ang II were statistically significant ranging from $37-68 \%(\mathrm{p}<0.05$ or 0.01$)$, as determined by at least three independent experiments. To date, there is no selective inhibitor for NADPH oxidase, and DPI, used in this study, has been used to inhibit NADPH oxidase in vitro (25). Since $\mathrm{H}_{2} \mathrm{DCFH}$ generated from $\mathrm{H}_{2} \mathrm{DCFH}-\mathrm{DA}$ hydrolysis is rapidly oxidized to fluorescent $\mathrm{DCF}$ in the presence of intracellular ROS, we measured DCF-derived fluorescence as a surrogate marker for intracellular ROS levels. This sensitive and reliable approach has been widely used in cellular oxidative injury studies (35-37). Taken together, the findings derived from the in vitro models used in this study are reliable.

Our present data demonstrate that NADPH oxidasedependent ROS generation mediates the accumulation of ECM and EMT induced by Ang II in rat peritoneal mesothelial cells. These findings suggest a potentially important role of NADPH oxidase activity in Ang II-induced peritoneal fibrosis. The putative mechanisms by which Ang II initiates NADPH oxidase-dependent ROS generation with up-regulation of PAI-I and $\alpha$-SMA evoke novel potential therapeutic targets in the prevention and treatment of peritoneal fibrosis.

\section{Acknowledgements}

We thank Merck, Sharp \& Dohme Pty, Ltd. (Whitehouse Station, NJ) for kindly providing losartan in this experiment. This study was supported by grants from the National Natural Science Foundation of China (Grant no. 30771012).

\section{References}

1. Williams JD, Craig KJ, Topley N, et al: Morphologic changes in the peritoneal membrane of patients with renal disease. J Am Soc Nephrol 13: 470-479, 2002.

2. Ha H, Cha MK, Choi HN and Lee HB: Effects of peritoneal dialysis solutions on the secretion of growth factors and extracellular matrix proteins by human peritoneal mesothelial cells. Perit Dial Int 22: 171-177, 2002.

3. Gotloib L, Wajsbrot V, Cuperman Y and Shostak A: Acute oxidative stress induces peritoneal hyperpermeability, mesothelial loss, and fibrosis. J Lab Clin Med 143: 31-40, 2004.

4. Rampino T and Dal Canton A: Peritoneal dialysis and epithelialto-mesenchymal transition. N Engl J Med 348: 2037-2039, 2003.

5. Lee HB, Yu MR, Song JS and Ha H: Reactive oxygen species amplify protein kinase $\mathrm{C}$ signaling in high glucose-induced fibronectin expression by human peritoneal mesothelial cells. Kidney Int 65: 1170-1179, 2004.

6. Aroeira LS, Aguilera A, Selgas R, et al: Mesenchymal conversion of mesothelial cells as a mechanism responsible for high solute transport rate in peritoneal dialysis: role of vascular endothelial growth factor. Am J Kidney Dis 46: 938-948, 2005.

7. Shen WL, Gao PJ, Che ZQ, et al: NAD(P)H oxidase-derived reactive oxygen species regulate angiotensin-II induced adventitial fibroblast phenotypic differentiation. Biochem Biophys Res Commun 339: 337-343, 2006.

8. Azhar M, Schultz Jel J, Grupp I, et al: Transforming growth factor beta in cardiovascular development and function. Cytokine Growth Factor Rev 14: 391-407, 2003.

9. Ruiz-Ortega M, Ruperez M, Esteban V, et al: Angiotensin II: a key factor in the inflammatory and fibrotic response in kidney diseases. Nephrol Dial Transplant 21: 16-20, 2006.

10. Bader M, Peters J, Baltatu O, Müller DN, Luft FC and Ganten D: Tissue renin-angiotensin systems: new insights from experimental animal models in hypertension research. J Mol Med 79: 76-102, 2001. 
11. Noh H, Lee HB, Yu MR, Kim YO, Kim JH and Lee HB: Angiotensin II mediates high glucose-induced TGF-betal and fibronectin upregulation in HPMC through reactive oxygen species. Perit Dial Int 25: 38-47, 2005

12. Sawada T, Ishii Y, Tojimbara T, Nakajima I, Fuchinoue $S$ and Teraoka S: The ACE inhibitor, quinapril, ameliorates peritoneal fibrosis in an encapsulating peritoneal sclerosis model in mice. Pharmacol Res 46: 505-510, 2002.

13. Evans JL, Goldfine ID, Maddux BA and Grodsky GM: Oxidative stress and stress-activated signaling pathways: A unifying hypothesis of type 2 diabetes. Endocr Rev 23: 599-622, 2002.

14. Li JM and Shah AM: ROS Generation by nonphagocytic NADPH oxidase: potential relevance in diabetic nephropathy. J Am Soc Nephrol 14: S221-S226, 2003.

15. Touyz RM: Reactive oxygen species and angiotensin II signaling in vascular cells - implications in cardiovascular disease. Braz J Med Biol Res 37: 1263-1273, 2004.

16. Kimura S, Zhang GX, Nishiyama A, et al: Role of NAD(P)H oxidase- and michotodria-derived reactive oxygen species in cardioprotection of ischemic reperfusion injury by angiotensin II Hypertension 45: 860-866, 2005.

17. Li JM and Shah AM: Mechanism of endothelial cell NADPH oxidase activation by angiotensin II. J Biol Chem 278: 12094-12100, 2003.

18. Alvarez Y, Pérez-Girón JV, Hernanz R, et al: Losartan reduces the increased participation of cyclooxygenase-2-derived products in vascular responses of hypertensive rats. J Pharmacol Exp Ther 321: 381-388, 2007.

19. Bataller R, Schwabe RF, Choi YH, et al: NADPH oxidase signal transduces angiotensin II in hepatic stellate cells and is critica in hepatic fibrosis. J Clin Invest 112: 1383-1394, 2003.

20. Akiba T, Ota T, Fushimi K, et al: Water channel AQP21 in the primary cell culture of rat peritoneum. Adv Perit Dial 15: 3-6, 1999.

21. Ha H, Yu MR, Choi YJ, Kitamura M and Lee HB: Role of high glucose-induced nuclear factor- $\kappa \mathrm{B}$ activation in monocyte chemoattractant protein-1 expression by mesangial cells. J Am Soc Nephrol 13: 894-902, 2002.

22. Rhyu DY, Yang YQ, Ha H, et al: Role of reactive oxygen species in TGF- $\beta$-induced mitogen-activated protein kinase activation and epithelial-mesenchymal transition in renal tubular epithelial cells. J Am Soc Nephrol 16: 667-675, 2005.

23. Chen L, Liu BC, Zhang XL, Zhang JD, Liu H and Li MX: Influence of connective tissue growth factor antisense oligonucleotide on angiotensin II-induced epithelial mesenchymal transition in HK2 cells. Acta Pharmacol Sin 27: 1029-1036, 2006.
24. Volpini RA, da Silva CG, Costa RS and Coimbra TM: Effect of enalapril and losartan on the events that precede diabetic nephropathy in rats. Diabetes Metab Res Rev 19: 43-51, 2003.

25. Park SY, Song CY, Kim BC, Hong HK and Lee HS: Angiotensin II mediates LDL-induced superoxide generation in mesangial cells. Am J Physiol Renal Physiol 285: F909-F915, 2003.

26. Ha H and Lee HB: Reactive oxygen species and matrix remodeling in diabetic nephropathy. J Am Soc Nephrol 14 (8 Suppl 3): S246-S249, 2003

27. Jiang ZP, Seo J, Ha H, et al: ROS mediate TGF- $\beta 1$-induced plasminogen activator inhibitor-1 upregulation in mesangial cells. Biochem Biophys Res Commun 309: 961-966, 2003.

28. Lee HB, Yu MR, Yang YQ, Jiang Z and Ha H: Reactive oxygen species-regulated signaling pathways in diabetic nephropathy. J Am Soc Nephrol 14 (8 Suppl 3): S241-S245, 2003.

29. Babior BM: NADPH oxidase: an update. Blood 93: 1464-1476, 1999.

30. Babior BM, Lambeth JD and Nauseef W: The neutrophil NADPH oxidase. Arch Biochem Biophys 397: 342-344, 2002.

31. Nauseef WM: Assembly of the phagocyte NADPH oxidase. Histochem Cell Biol 122: 277-291, 2004.

32. Landmesser U, Cai H, Dikalov S, et al: Role of p47(phox) in vascular oxidative stress and hypertension caused by angiotensin II. Hypertension 40: 511-515, 2002.

33. Mizuki K, Takeya R, Kuribayashi F, et al: A region C-terminal to the proline-rich core of $\mathrm{p} 47 \mathrm{phox}$ regulates activation of the phagocyte NADPH oxidase by interacting with the C-terminal SH3 domain of p67phox. Arch Biochem Biophys 444: 185-194, 2005.

34. Kiribayashi K, Masaki T, Naito T, et al: Angiotensin II induces fibronectin expression in human peritoneal cells via ERK1/2 and p38 MAPK. Kidney Int 67: 1126-1135, 2005.

35. Lee YJ, Heo JS, Suh HN, Lee MY and Han HJ: Interleukin-6 stimulates alpha-MG uptake in renal proximal tubule cells: Involvement of STAT3, PI3K/Akt, MAPKs, and NF-kappaB. Am J Physiol Renal Physiol 293: F1036-F1046, 2007.

36. Tang EH, Leung FP, Huang Y, et al: Calcium and reactive oxygen species increase in endothelial cells in response to releasers of endothelium-derived contracting factor. Br J Pharmacol 151: 15-23, 2007.

37. Wan J and Winn LM: Benzene's metabolites alter c-MYB activity via reactive oxygen species in HD3 cells. Toxicol Appl Pharmacol 222: 180-189, 2007. 